New defence science chief offers cash to UK universities

UNIVERSITY and polytechnic scientists should become more closely involved in helping to determine strategies for defence research, according to Professor Ron Mason, the newly-appointed chief scientist to the UK Ministry of Defence.

Even five years ago, such a statement would have generated hostility from university colleagues and students alike. Both were concerned-for different $\sum_{i}$ reasons -- with intrusions into the "purity" of research. Yet when Professor Mason's appointment was announced at a meeting last week at the University of Sussex, where he has been professor of chemistry since 1971, even a student representative present greeted it, he says, with applause.

With the continued squeeze on university funding, and a growing acceptance of department-sponsored research, Professor Mason claims that there now exists a "more relaxed view" in universities about accepting military funds than a few years ago.

As chief scientific adviser-considered by many to be the highest position that any British scientist can hold in government-one of his main tasks will be to act as an interface with the scientific community. And the new atmosphere should, he feels, make this easier to achieve.

"One of the first things I want to engage in is a discussion on the relative balance of intermural and extramural research, and personally I would like to see a substantial increase, so broadening the base of expertise and advice," Professor Mason said this week.

He emphatically rejects the notion canvassed by the Campaign for Nuclear Disarmament and others that university scientists should refuse to carry out military research on principle. A scientist's responsibility should be to produce first-rate research in pursuit of aims determined by the conventional political processes.

"The proviso, of course, is that all research carried out on Ministry of Defence contracts should ultimately be publishable in the normal way; as a university man, I would be worried if an academic institution accepted any restrictions on publication." Professor Mason has himself in the past received funds from the Microbiological $\mathrm{Re}$ search Establishment at Porton Down in support of certain aspects of his work on ion transportation across cell

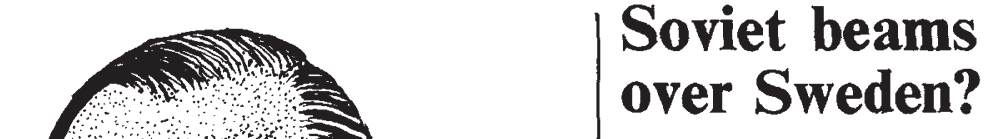

Is the Soviet Union developing a charged-particle anti-satellite weapon? Reports earlier this year listed evidence that tests of such a weapon had been carried out at a research facility near the Soviet city of Semipalatinsk, and described the debate raging between the US Air Force, convinced that the tests were being carried out, and the more skeptical CIA. A Swedish scientist has now published some findings that will add to the speculation.

Dr Lars Erik de Geer of the National Defence Research Institute detected traces of radionuclides neptunium-239 and molybdenum-99 in the atmosphere over southern Sweden on five occasions during the first half of 1976 . The same atmospheric samples also contained small amounts of fission products iodine-131 and barium-140. On the first two occasions - in late February, and March-the prevailing winds had been from the east during each period of three days when the nuclides had arrived. On the other three occasionsin April, May and June-the winds had blown from the east on at least two days in each week during which the nuclides came. Dr de Geer thus postulates that "the material arrived in Sweden by way of southern Finland or western USSR and the Baltic Sea".

What could have caused such activity? The short answer is: no known source. The amounts of neptunium and molybdenum detected are compatible with the ratios found in debris that circulates for a few weeks after the explosion of a nuclear bomb. But, as Dr de Geer points out, if these nuclides resulted from some fission process, it is strange that other short-lived fission products (such as tellurium-132) were not also detected. Neither is the composition of the samples consistent with discharge from an ordinary nuclear power reactor. $\mathrm{He}$ wonders whether some laboratory experiment involving fresh fission products could have been responsible; but a check on research laboratories in Sweden, Denmark and Finland showed that no such work was in progress during the period in question. The talk to people in universities help find the reasons for this situation."

Professor Mason admits to being slightly "bewildered and overwhelmed" by the scope of his new job, which he takes up on 1 March, 1978 on a threeyear secondment from the university.

$\mathrm{He}$ is convinced that the key to its success, at least in developing links between the scientific community and the defence establishment, lies in opening up discussion about military research; but whether closer liaison is acceptable to either party remains to be seen.

David Dickson

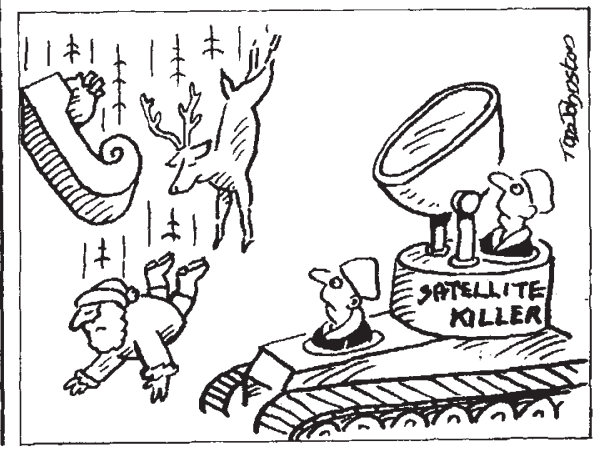


most exotic explanation-that the nuclides were produced by chargedparticle beam experiments in the Soviet Union-seems to fit in that the observations were made at the same time as the experiments at Semipalatinsk were reportedly started. According to meteorological trajectories, however, nuclides from this area of the USSR could have been carried to southern Sweden in March, April and May, but probably not in February or July. This means that, although the nuclides detected in February were deposited by an easterly wind, they probably came from a source other than Semipalatinsk. Given the nuclides' short half-lives (ranging from 2.35 days for neptunium-239 to 12.79 days for barium-140), and the distance from Semipalatinsk to Sweden (about 4,000 $\mathrm{km}$ ), the winds carrying the nuclides would have to have been strong. Although meteorological data suggests that the winds probably would have been strong enough, sufficient doubt remains for Dr de Geer to cite this as a factor against the Soviet source.
Dr Kay Edvarson, of the National Institute for Radiation Protection, comments that it is impossible to pinpoint a unique source for such activity. "We have fairly extensive surveys made now on releases from power reactors, and Dr de Geer's findings don't really fit any reactor types known to us. The National Defence Research Institute quite often detects some radioactivity which can not have come from a nuclear test. These samples are generally assumed to have come from small, localised sources such as a hospital. But it is impossible that the sort of activity Dr de Geer detected can have come from such a source. On three occasions the nuclides were detected at several sampling stations in southern Sweden, so it's highly improbable that the source was localised. It has to be reasonably far away, and strong. If it had been a strong source somewhere in the Nordic countries or West Germany, we would have heard about it." He points out that the probability of detecting the sorts of samples now under discussion is small.
"They would be masked by fairly fresh debris from a nuclear test", he says, "and the release time has to coincide with the wind pattern".

Dr Bhupendra Jasani, of the Stockholm International Peace Research Institute (SIPRI), says it is difficult to think of any sources other than those mentioned by Dr de Geer which might have caused the activity. "I am very skeptical of those who claim that the Russians have a charged-particle beam weapon in operation", he says. "However, the Soviets are pioneers in accelerator physics and accelerators, and they could well be working on such weapons-just as the Americans may be." Dr de Geer's report, published in Science, quickly drew a statement from the Pentagon questioning the hypothesis of the Soviet source. But, as Dr de Geer points out, "I am not saying that the nuclides came from charged-particle beam weapon tests in the USSR. It is simply that, as no other source seems to fit, the possibility that they did has to be considered."

Wendy Barnaby

\section{Sweden follows US example on aerosols}

SWEDEN is to become the first country in Europe to ban the manufacture and use of chlorofluorocarbon (CFC) propellant gases in aerosol sprays.

The ban, which will take effect in 1979, reflects public concern at the possibility that such gases may deplete the stratospheric ozone layer, hence potentially reducing the atmosphere's ability to screen ultra-violet rays, and leading to an increase in skin cancer.

In the US, fears that the extensive use of CFC gases could cause a decrease of ozone of up to $14 \%$ over a period of 100 years have already led to a similar ban, the result of a joint decision by the Food and Drug Association, the Environmental Protection Agency, and the Consumer Product Safety Committee.

Sweden is the first country in Europe to follow the American example. The Swedish Government's action is based on a recommendation of its Products Control Board that a licensing system should be introduced for aerosols, and that such licences be withheld from most aerosols using CFC gases.

The manufacture and import of such sprays--excluding certain products required for special uses such as medicine-will be banned from the beginning of January 1979, and their sale from the following June.

The move has already brought reaction from a number of Sweden's trading partners in the European Free Trade Association (EFTA), concerned at the economic impact it may have. Finland, for example, which exports many aerosols to Sweden, has asked Stockholm either to withdraw the ban, or to extend the timescale considerably.

The Finnish request is based on the position held by the majority of Euro-

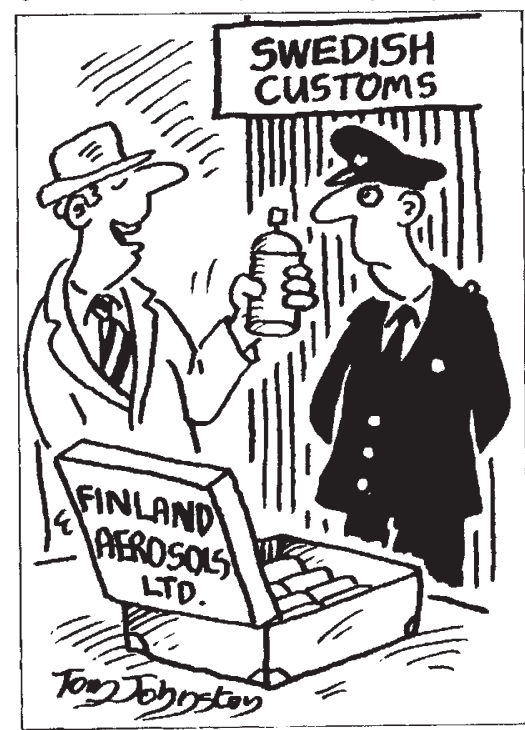

"It's an aerosol for getting

rid of Finnish aerosol salesmen"

pean countries that although CFC aerosols represent a theoretical danger to the ozone layer, no substantial evidence has yet been produced to indicate that any significant depletion of ozone does indeed take place.

Widespread public controversy has surrounded the issue since the possibility of such depletion was raised by
Rowland and Molina in 1974. It is this concern that has led to the current ban in the US, where many manufacturers are turning to the use of hydrocarbon gases as an alternative.

No theoretical model of the chemical interaction between ozone and CFCs in the atmosphere, however, has yet produced an adequate representation of what actually happens. In particular, most models rely on a one-dimensional interaction, and are hence unable to take into account the full three-dimensional movement in the stratosphere.

In view of the scientific uncertainties, countries such as Britain, Germany and France have decided that more research is needed before a decision about whether or not to ban CFC aerosols. The EEC has recommended that a review of the situation be made in the second half of 1978, and has also commissioned the UKbased consultants METRA to carry out an economic impact study on the effects of a ban.

The Swedish government has therefore decided to break ranks with other European countries, and in particular its Scandinavian neighbours. However the decision is likely to be welcomed in the US, where FDA commissioner Donald Kennedy said earlier this year that since the threat of ozone depletion was a global problem, he hoped other countries would follow suit.

An official of the Swedish Department of Industry said in Stockholm last week. "The Swedish philosophy is that this will take a long time, and someone has to take the lead."

David Dickson 